\title{
铯 L Los movimientos de mujeres y feministas en la transición de posguerra y su aporte a los cambios socioculturales en El Salvador
}

\author{
María Candelaria Navas \\ Universidad de El Salvador
}

Resumen: Este ensayo propone una periodización para el estudio de las mujeres organizadas y no organizadas en El Salvador desde aproximadamente 1841 hasta 2008. Se identificaron seis períodos y cuatro hechos históricos que marcaron algunos cambios socioculturales desde la perspectiva de género, para las mujeres salvadoreñas y para la sociedad. El trabajo parte de la lucha sufragista con Prudencia Ayala hacia 1930, hasta la consecución del voto femenino en 1950. En 1957 surge la Fraternidad de Mujeres Salvadoreñas, constituida por mujeres de la clase trabajadora, cuya tarea era apoyar las luchas sindicales. Luego se hace referencia a la transición de las exguerrilleras a feministas, con el surgimiento de las organizaciones de mujeres que incorporan la perspectiva de género. El trabajo cierra con un análisis de las principales agendas y estrategias del Movimiento de Mujeres y Feminista (MM y F) de 1992 a 2008.

Palabras clave: Movimiento de mujeres, movimiento social, feminismo, Acuerdos de Paz, derechos.

Abstract: This essay proposes a periodization for the study of organized and non-organized women in El Salvador from around 1841 to 2008. Six periods and four historical events that brought sociocultural 
change from the perspective of gender for salvadoran women and society. This study begins with the suffragist struggle of Prudencia Ayala in the 1930's until the attaintment of femenine vote in 1950. In 1957, emerges the Fraternidad de Mujeres Salvadoreñas constituted by working class women, whose tasks were to support labor union struggles. Then it deals with the transition from former female guerrilla fighters to femenists, with the emergence of women organizations that incorporated geneder perspective in El Salvador. The essay closes with the main agendas and strategies of the Movimiento de Mujeres y Feministas (MM y F) from 1992 to 2008.

Keywords: Women's movement, social movement, feminism, Peace Agreements, rights.

Yo no deseo que las mujeres tengan poder sobre los hombres, sino sobre ellas mismas.

\section{Introducción}

La frase anterior es de derechos de las mujeres no sólo se ha Mary Wollstonecraft, autora librado en la calle, también en todos de Vindicación de los derechos de los ámbitos del quehacer humano. El la mujer. Escribió la frase en 1759, Salvador no es la excepción. después de leer en un informe de la Asamblea Nacional francesa que ellas "solo debían recibir educación relacionada con el ámbito doméstico". Desde entonces, la lucha por los

La investigadora del Instituto de la Paz y los Conflictos de la Universidad de Granada, Cándida Martínez López, sostiene que:

La paz ha sido representada a lo largo de nuestra historia como mujer. La paz nació con cuerpo y atributos femeninos en la antigua Grecia, encarnada en la diosa Eirene, y su figura, relacionada siempre con la prosperidad y el bienestar a lo largo de los siglos. (Martínez López, C. E. y Pax, 1998, pp. 239-261).

Un complejo mundo simbólico alrededor de dicha percepción también ha contribuido a una construcción muy particular de las relaciones de género.
La paz como abstracción ha sido considerada mujer, asimilándole virtudes, potencialidades y símbolos considerados femeninos; así nos referimos a la paz y fertilidad; paz y 
abundancia; paz y vida; paz y capacidad de creación son algunas de las asociaciones transmitidas en textos e imágenes a lo largo de la historia.

Esa idea ha sido transmitida a través de la figura femenina con niños en los brazos o en su regazo significando fertilidad y paz, mujeres portando la cornucopia como símbolo de abundancia, entre otras. Entre las 128 personas laureadas con el Premio Nobel de la Paz entre 1901 y 2014, sólo figuran 16 mujeres. Algunas de ellas fueron clave en la resolución de conflictos bélicos o en proyectos de tejido comunitario y sororidad.

Reflexionando sobre el tema me pregunto: ¿Somos las mujeres más pacíficas que los hombres?

Esa pregunta ameritaría talleres de lectura y reflexión intensivos. De momento, podríamos adelantar que, precisamente, la identificación de las mujeres con la paz probablemente se apoya en el histórico alejamiento de las mujeres de los aparatos de poder, de los ámbitos de donde se toman las decisiones acerca de la guerra, la diplomacia y los asuntos internacionales, y también sobre su experiencia de la maternidad que requiere en la lactancia y crianza mantenerse en el ámbito privado.

Sin embargo, como sabemos, ser madre no equivale a ser pacífica, y las mujeres salvadoreñas, por ejemplo, han participado de diferentes formas ante los gobiernos represivos: militantes, guerrilleras, correo durante la guerra y dirigentas enfrentándose a la oligarquía y a la dictadura militar, lo cual demuestra que no somos pacíficas por naturaleza. Sin embargo, de acuerdo con cifras de las Naciones Unidas, las mujeres representan el $8 \%$ de quienes participan en las negociaciones de paz, y menos del $3 \%$ de quienes firman acuerdos de paz. Siempre me he preguntado por qué en las fotos de la firma de los Acuerdos de Paz en El Salvador no hay ninguna mujer de las comandantas y guerrilleras que estuvieron al frente de la guerra.

En 1988, la primera marcha para conmemorar el 8 de marzo concentró a cerca de 6,000 mujeres, cuando por primera vez en la historia de El Salvador convocó el incipiente Movimiento de Mujeres. Con un clavel rojo y una paloma de papel en las manos llegaron a la plaza Cívica frente a Catedral Metropolitana para celebrar una oración por la paz y denunciar la situación de la mujer en medio de la guerra. Se pronunciaron contra el reclutamiento forzoso y a favor de una solución política negociada al conflicto, coreando consignas en la marcha como: "La mujer presente en la lucha por la paz"; "Por la dignidad de la mujer todas a luchar"; "Mujer que se organiza, mujer que se libera" 
y "Alto al reclutamiento forzoso de nuestros hijos".

En diciembre de ese mismo año, se realizó el Primer Encuentro de Mujeres por la Paz en El Salvador, organizado por el Instituto de Investigación y Capacitación de Desarrollo de la Mujer (IMU), con la asistencia de 300 mujeres de sectores populares y representantes de organizaciones o asociaciones vinculadas a la lucha social del pueblo salvadoreño.

Las mujeres concluyeron que la causa principal de la desintegración familiar salvadoreña son las injustas estructuras sociales que sumen en la miseria y en la opresión a las grandes mayorías marginadas (Navas, 1988, p. 3).

Después de la firma de los Acuerdos de Paz en 1992, comienza en El Salvador una nueva fase histórica. Los movimientos sociales y los movimientos de mujeres y feministas son impactados por los cambios que se experimentan al pasar de la guerra a la paz, así las mujeres sienten la necesidad de pasar de ser objetos a ser sujetas sociales.

Antes de la guerra, los movimientos sociales clásicos giraban alrededor de las demandas de clase por mejorar salarios, horarios y asistencia social. Luego, durante la guerra civil, se convirtieron en movimientos populares revolucionarios y se incorporaron a la estrategia revolucionaria por una nueva sociedad. En la posguerra, los nuevos movimientos sociales necesitaban recrear sus planteamientos teóricos y metodológicos para su accionar e interpretación.

\section{El Movimiento de Mujeres y} Feministas (MMyF) como sujeto social transformador y ante el surgimiento de nuevas organizaciones con demandas específicas del ser mujer, debieron recurrir a interpretaciones explicativas sobre las relaciones sociales entre hombres y mujeres, y las disparidades de género en los diferentes espacios sociales, económicos, políticos y culturales. Esto les permitió iniciar los Estudios de Género en El Salvador, asumiéndose como sujetas transformadoras.

\section{Probablemente, el Movimiento} de Mujeres y Feministas sean el movimiento social más dinámico y sostenible de todos los que surgieron en la posguerra, los cuales aprovechando los espacios democráticos abiertos por los Acuerdos de Paz lograron colocar el tema de la discriminación genérica en la agenda nacional, creando cierta "masa crítica" en algunos sectores sociales y políticos de la sociedad salvadoreña. Colocaron en primer plano la desigualdad genérica que es producto de las relaciones desiguales de poder que habían permanecido ocultas y naturalizadas. 
La lucha de las mujeres ha sido por visibilizar la desigualdad y la discriminación, justamente el subvertir ese orden establecido le confiere sentido político a su lucha. De hecho, logró romper el histórico divorcio entre el Estado y el movimiento popular al involucrarse de lleno en la elaboración de la Política Nacional de la Mujer, en 1996, antes de la creación del Instituto Salvadoreño de Desarrollo de la Mujer (ISDEMU).

\section{Antecedentes}

El Movimiento de Mujeres y Feministas en El Salvador es de una larga data, sin embargo, la incorporación del feminismo y de la perspectiva de género en sus planteamientos y demandas es reciente, aproximadamente 32 años, con la fundación de dos organizaciones: Organización de Mujeres por la Paz (ORMUSA), que surge en 1985, y el Instituto de Investigación, Capacitación y Desarrollo de la Mujer (IMU), en 1986. Estas fueron las primeras organizaciones de mujeres que en su misión y visión inicial se plantearon la lucha específica por los derechos de las mujeres.

Para el estudio de esta particularidad del MMyF se considera pertinente presentar un antes y un después de este suceso histórico. Un antes, que se remonta lejanamente a 1841, año de fundación de la Universidad de El Salvador y un después que son los 25 que han transcurrido desde la firma de los Acuerdos de Paz de 1992 a 2017. Vale aclarar que nuestro estudio se cierra en 2008.
A la luz de los planteamientos teórico-metodológicos feministas presento a continuación la síntesis de una propuesta de periodización y su respectivo desarrollo y análisis sobre el aporte que las mujeres, individualmente o en grupo, han dado a los cambios políticos y socioculturales en El Salvador.

Desde la segunda mitad del siglo XIX, a lo largo del siglo XX e inicios del XXI, las mujeres aparecen como fuerza organizada o como personas individuales en distintos espacios: sectoriales, gremiales, corporativistas o literarios.

La demarcación de los períodos que se propone no es arbitraria, para su definición se han tomado en consideración elementos coyunturales como:

a) Que los hechos que inician o cierran el período sean de trascendencia para las mujeres y que estén relacionados con aspectos educativos, legales y organizativos. 
b) Que los hechos trasciendan a la sociedad de manera estructural e impacten a mujeres y hombres.

c) Que se ubiquen dentro de una coyuntura nacional o internacional que influya de alguna manera en la implementación de medidas a favor de los derechos de las mujeres.

A partir de las consideraciones y referencias anteriores se proponen seis períodos para el estudio del MMyF, desde 1841 hasta 2008.

Primer período: durante la segunda mitad del siglo XIX, con el antecedente de la creación de la Universidad de El Salvador (1841) y el parcial acceso de las mujeres a la educación, el protagonismo de las primeras bachilleras y la primera graduada universitaria, hasta la segunda mitad de la década de los años 50 del siglo XX con la creación en 1956/57 de la Organización Fraternidad de Mujeres Salvadoreñas, ligada al movimiento obrero del Partido Comunista Salvadoreño, creado en 1930.

Para analizar la participación sociopolítica de las mujeres salvadoreñas se inicia con la exploración de los espacios de acción de mujeres independientes y grupos organizados. Se remarcan dos hechos: la presencia de Prudencia Ayala y su autoproclamación como candidata a la presidencia de la República, en 1930, y la obtención del voto femenino en 1950. Asimismo se destacan aquellas intelectuales que comienzan a incursionar en la política, la literatura y las artes.

Segundo período: de 1957 a 1975, la creación de Fraternidad de Mujeres cierra el período anterior y abre este período que se caracteriza por el surgimiento de las primeras organizaciones exclusivamente femeninas, cuyo énfasis era sectorial, aunque elaboraron reivindicaciones y estrategias de acción propias ligadas a la esfera doméstica. Las mujeres se integran a las diferentes organizaciones que conforman el movimiento popular e incluyen sus demandas de clase dentro de la plataforma de las demandas populares. Se analiza el ascenso del movimiento popular revolucionario, el inicio de la lucha armada y la guerra civil salvadoreña con la presencia femenina en sus filas.

Tercer período: de 1975 a 1985, el inicio de la Década de la Mujer en 1975-1985, instaurada por las Naciones Unidas, abre este período que da pautas y ejerce cierto tipo de influencia y presión a nivel gubernamental, y a las mujeres les abre ventanas y motivaciones para dar los saltos que les permite trascender la esfera doméstica y dar forma a lo que a futuro será el Movimiento de Mujeres y Feministas (MMyF) salvadoreño. Justamente surge la "Primera oleada" de organizaciones femeninas, muchas de ellas conformadas en el exilio y otras dentro del país, para 
apoyar la lucha popular. La característica principal de estas organizaciones de mujeres es la nula reivindicación de género en sus objetivos, demandas o plataformas. Este período coincide con el auge del conflicto armado y las migraciones masivas dentro y fuera del país por razones políticas. También fue la apertura para la creación de organizaciones que trascenderían el análisis de clase para integrar el análisis de género.

Cuarto período: de 1986 a 1989, "Segunda oleada" de organizaciones provenientes de agrupaciones políticas de izquierda, que comienzan a analizar "la problemática de la mujer", lejos de asumirse feministas. Todavía la guerra civil se encontraba en su accionar. Justamente con el inicio del período aparece el Instituto de Investigación, Promoción y Desarrollo de la Mujer (IMU) desde la sociedad civil. Específicamente, son mujeres del Partido Comunista sus fundadoras y de la Organización de Mujeres Salvadoreñas por la Paz (ORMUSA). Cierra el período la ofensiva guerrillera de noviembre de 1989, en la cual es asesinada la fundadora del IMU, Norma Virginia Guirola de Herrera, y se abren los cauces para un cierre negociado a la guerra civil.

Quinto período: de 1990 a 1992, la "Tercera oleada", se enmarca en el desenlace de la guerra civil. Con las organizaciones creadas en los períodos anteriores se empieza a perfilar el actual Movimiento de
Mujeres y Feministas (MMyF) y a integrar la perspectiva de género en las demandas y denuncias. Asimismo se empieza a dar una dimensión regional $e$ internacional al incipiente movimiento, pues desde su primera participación en los Encuentros Feministas Latinoamericanos y del Caribe, en 1987, participarán en los futuros Encuentros.

Sexto Período: de 1993 a 2008, fase de transición de posguerra. Este período se abre con la realización en El Salvador del VI Encuentro Feminista Latinoamericano y del Caribe, elevándose así su accionar a nivel nacional, regional e internacional. Consolidación del Movimiento de Mujeres en El Salvador y el surgimiento de algunas experiencias organizativas de mujeres rurales. $^{2}$

Para dar contenido y justificar la propuesta de periodización se ha realizado una revisión socio-histórica sobre la participación y los aportes individuales y colectivos de las mujeres a los cambios socio-culturales y políticos en El Salvador, complementando con entrevistas personales, esto con el objetivo de fundamentar los aportes generacionales o de acciones de grupos de mujeres, lo cual ha significado una valiosa fuente para estudiar las inquietudes que se estaban despertando con respecto al feminismo y a los roles de las mujeres en la sociedad salvadoreña de las diferentes generaciones. 
Como Movimiento de Mujeres y Feministas (MMyF) se reconoce aquel que está constituido por todos los espacios organizativos que las mujeres conforman para enfrentar, socializar, reconocer y resolver necesidades e intereses ligados a su condición de género subordinado y discriminado. Se caracteriza por la búsqueda de cambios que mejoren la condición $\mathrm{y} / \mathrm{o}$ posición de las mujeres en la sociedad. Además, se construye y deconstruye permanentemente.

Se considera que en el contexto posconflicto (1992 en adelante), el accionar de los movimientos sociales, el movimiento de mujeres y sus diferentes expresiones: feminista, lésbico, de la diferencia, entre otros, constituyen una nueva parte del mismo.

Sin embargo, desde una perspectiva histórica, al relacionar dicho movimiento con el accionar de las organizaciones de mujeres se encuentran tres momentos:

Las organizaciones de mujeres ligadas al movimiento obrero en el marco de la lucha de clases, 19201970.
Las organizaciones de mujeres apoyando el proyecto contra-hegemónico, en el marco de los "movimientos populares revolucionarios", 1971-1992.

Las organizaciones de mujeres con reivindicaciones propias o de género, que corresponden al momento en que surgen las demandas específicas del ser mujer, 1992-2008.

En los dos primeros momentos, los sectores subalternos se constituían a partir de su determinación e identidad de clase. Consecuentemente, las mujeres $\mathrm{y} / \mathrm{o}$ sus organizaciones debían "sumar fuerzas" a otros movimientos, a otras reivindicaciones de carácter global. Las transformaciones estructurales, a ese nivel, resolverían todas las formas de opresión, incluida la de género.

Las salvadoreñas se integraron a estas luchas sociales con reivindicaciones propias, como se ha señalado antes, aproximadamente entre 1987 y 1992, momento en que se fundan las primeras organizaciones que incorporan la perspectiva de género.

Este hecho se confirma en la cita siguiente:

Los primeros intentos organizativos de las mujeres, no provinieron de ellas mismas, y como consecuencia de ello, sus demandas y reivindicaciones giraban en torno a las de la organización que las impulsaba; sería hasta el fin de la guerra, que 
algunas lograron hacer suyo un discurso de género. (Soriano Hernández, s.f. p. 7).

Al iniciar este análisis partimos de la consideración de que el Movimiento de Mujeres y Feministas, 1985-2008, es parte del movimiento social salvadoreño, dado que ha sido expresión de la acción de las mujeres en procesos históricos y culturales, y además cumple con los requisitos académicos mínimos para ser catalogado como tal.
Ante la imposibilidad de presentar, en esta oportunidad, el desarrollo de todos y cada uno de los períodos antes mencionados, doy a continuación un breve resumen de cuatro hechos históricos que marcaron algunos cambios socioculturales, desde la perspectiva de género, para las mujeres salvadoreñas y para la sociedad.

\section{1. ¿Hubo movimiento sufragista en El Salvador?}

El poco desarrollo industrial de $\mathrm{El}$ Salvador, el ambiente represivo de la época, la inestabilidad política junto a las actitudes retrógradas sobre el papel de las mujeres en la sociedad, contribuyeron a que se prolongaran las luchas sufragistas y que no se insertaran en la segunda ola del feminismo internacional representada en el sufragismo como demanda principal del movimiento feminista, a pesar de todo, no lograron impedir que Prudencia Ayala se autoproclamara candidata a la presidencia de la República en 1930. Para esa época, en El Salvador, las mujeres no tenían derecho al voto. Sin embargo, causa sensación la figura de Prudencia Ayala, quien se declara "orgullosa de ser una humilde india salvadoreña".

Prudencia Ayala se amparó en cierta apertura política esperando colocar el sufragio femenino en la agenda nacional, ya que la Constitución de 1886 no negaba de una manera explícita los derechos de las mujeres. Pero el argumento principal sobre el que basaba su solicitud para la inscripción de su nombre en el libro de votantes era que el término salvadoreño, que figuraba en la Constitución para definir a quienes tenían el derecho a la ciudadanía, amparaba a todos aquellos que ostentaban esta nacionalidad y, por tanto, siendo ella mujer nacida en territorio salvadoreño estaba implícitamente involucrada en esta acepción. En efecto, el artículo 51 de la época decía: "Son ciudadanos de la República todos los salvadoreños mayores de 18 años, los casados y los que hayan obtenido algún título literario aunque no hubiesen llegado a esa edad". Por su parte, "la ley electoral de la época tampoco hacía aclaración de ningún tipo sobre la interpretación genérica que 
debía darse al término salvadoreño" (Cáceres Prendes, 1993, p. 20).

Su plan de trabajo contemplaba no solamente el apoyo a los derechos de las mujeres, sino también el estímulo a la labor sindical, a la honradez en la gestión gubernamental, límites en el uso y abuso del alcohol, reconocer jurídicamente a las hijas e hijos nacidos fuera del matrimonio, entre otros.

Destaco cuatro hechos que a nuestro juicio son de trascendencia histórica y política:

a. Su osadía principal es haberse declarado candidata a la presidencia de la República y proyectar el Gran Partido Feminista Salvadoreño. Llegó a formular una propuesta de plan de gobierno. La demanda de Prudencia Ayala, que causó perplejidad entre los integrantes de una sociedad claramente patriarcal, podría haber tenido vigencia, ya que la Constitución de 1886 no negaba de una manera explícita los derechos de las mujeres. Sin embargo, el asunto se resolvió con argumentos de tipo procesal, sin que la Corte Suprema emitiera un fallo en torno a esa pretensión (Cáceres Prendes, 1993, p. 42).

b. La creación del periódico Redención Femenina, en el cual expresaba sus principales postulados y demandas sobre los derechos de las mujeres. Desde 1913 publicaba sus planteamientos feministas y su pensamiento unionista centroamericano. Fustiga a las dictaduras del istmo, apoya la lucha de Augusto César Sandino, en Nicaragua, y rechaza la intervención extranjera.

c. Presentarse como escritora cuando apenas había alcanzado a completar el segundo grado. Escribió dos libros: Amores de loca (1925) y Payaso literario en Combate (1928), además de dos folletos donde expone su pensamiento feminista: "Inmortal" y “Luz de Orión” (1924).

d. La creación del Círculo Femenino Tecleño, cuyo accionar desconocemos ya que no hemos encontrado documentos que lo sustenten.

La sociedad salvadoreña no supo cómo calificarla, se le llamó "loca" y "analfabeta". A Prudencia Ayala se le podría definir como una de las primeras sufragistas y promotora de la unión centroamericana.

Posteriormente en 1948, se aprobó la Convención sobre los Derechos Políticos y Civiles de la Mujer, por la ONU, que fue ratificada por El Salvador en 1951. En 1947, se 
fundó la Liga Femenina Salvadoreña, la cual gestionó el derecho al sufragio sin restricciones por las mujeres salvadoreñas en 1950. Esta organización tuvo un papel destacado en los años anteriores a la derogación del voto femenino en El Salvador. Fue de carácter cívico y promovida por algunas mujeres que ya habían participado en la Asociación de Mujeres Democráticas de El Salvador en los años 40.

La Liga Femenina en su lucha por las reivindicaciones de las mujeres planteó la necesidad de que se les concediera el derecho al voto y a la inclusión en la Constitución Política de 1950, asimismo que la enseñanza fuera impartida por el Estado, además de ser gratuita y laica. Otra de las conquistas de la Liga Femenina fue que se reconocieran los derechos de los hijos nacidos fuera del matrimonio. También gestionaron y lograron la creación de la Ciudad de los Niños.
El proceso de reconocimiento de los derechos políticos de las mujeres salvadoreñas, es decir, su primer eslabón en la construcción de su ciudadanía, el derecho a votar y a ser votada, tuvo características específicas y particulares que lo diferenciaron de la mayoría de los demás países de la región.

La no existencia de un movimiento sufragista, esto como consecuencia del aislamiento cultural y de la represión social que los regímenes autoritarios impusieron en el país desde comienzos del siglo XX.

Una activa participación de las mujeres en todos los movimientos sociales y políticos del país, sin reivindicaciones específicas de género.

El interés de los regímenes autoritarios de promover el otorgamiento de estos derechos a las mujeres, ello con el objetivo de capitalizar a su favor la votación femenina.

\section{La primera organización de mujeres populares: Fraternidad de Mujeres Salvadoreñas}

Fraternidad de Mujeres Salvadoreñas tiene como antecedente y contexto la cultura política gestada en el período 1930-1959, la que para historiadores como Cáceres Prendes (1993, p. 25) constituyó un período importante en la modernización del Estado salvadoreño, que estuvo caracterizado por: "una idea de nación que como representación de la identidad colectiva adquiere una dimensión especial en el concepto de ciudadanía".

Desde finales de los años 40 se produjeron interesantes transformaciones en la cultura nacional alrededor de la organización política de 
las mujeres que tuvieron destacada participación en el derrocamiento del dictador Maximiliano Hernández Martínez y en la obtención del voto femenino en los años 50, expresando así una nueva forma de identidad política: la mujer ciudadana.

En esa época se destacan dos modalidades de participación de las mujeres: la participación directa en las organizaciones sociales mixtas: sindicatos, estudiantiles, campesinas, magisteriales, comunales y las organizaciones de mujeres creadas como mecanismos de incorporación de sectores sociales no vinculados a las organizaciones sociales antes señaladas sino como amas de casa, trabajadoras independientes y profesionales.

Al interior del movimiento sindical, la proporción de mujeres incorporadas es un poco mayor a partir de su inserción en el mercado laboral salvadoreño desde muy temprana edad, esto dadas las condiciones económicas y sociales del país. De ahí que probablemente su participación haya sido mayor que dentro de las organizaciones campesinas.

Existen datos sobre la incorporación de las mujeres en los sindicatos a partir de 1986, de los años anteriores no existen registros. En este año, la membresía sindical femenina es aproximadamente el $50 \%$. $\mathrm{Si}$ incluimos al sector magisterial en donde aproximadamente el 75\% está constituido por mujeres, probablemente las mujeres eran la categoría mayoritaria, de las obreras sindicalizadas es que surgirá la primera organización popular de mujeres.

En este período aparecen las primeras organizaciones exclusivamente femeninas, cuyo énfasis era sectorial, aunque plantearon reivindicaciones y estrategias de acción propias ligadas a la esfera doméstica. Las mujeres se integran a las diferentes organizaciones que conforman el movimiento popular e incluyen sus demandas de género dentro de la plataforma de las demandas populares.

El surgimiento de Fraternidad de Mujeres Salvadoreñas en 19561957 es un hecho trascendente para los movimientos femeninos, puesto que es la primera organización específica de mujeres en oposición al régimen que surgió en el seno de un partido político. Sus fundadoras tienen influencia del Partido Comunista Salvadoreño que fue fundado en 1930.

En sus inicios, el propósito de la organización fue aglutinar mujeres de las más variadas tendencias políticas y religiosas, sin embargo, al final participaron principalmente mujeres sindicalistas, mujeres de los mercados, algunas profesionales y maestras simpatizantes de las ideas de izquierda; sus actividades más 
destacadas estuvieron relacionadas con este sector.

Fraternidad de Mujeres Salvadoreñas estaba constituida principalmente por mujeres de la clase trabajadora. Sus principales tareas iban encaminadas a apoyar las luchas sindicales; sus bases de apoyo se encontraban en mujeres de todos los sectores sociales: señoras de los mercados, compañeras o esposas de obreros, estudiantes universitarias, profesionales y empleadas domésticas, también estaban las vendedoras de productos lácteos y vendedoras ambulantes que reclamaban el respeto a los derechos ciudadanos. Mediante un recurso de amparo lograron la protección para las señoras de los mercados, quienes eran perseguidas por la policía por realizar actividades económicas fuera de los mercados, también apoyaron a los presos políticos.
El triunfo de la Revolución cubana en 1959 conmocionó a la izquierda salvadoreña. Precisamente a finales de esa década hubo un repunte de los movimientos populares expresados en huelgas de trabajadores de aceros, de textiles, de transportistas, de maestros, entre otros. El creciente ascenso de dichos movimientos coincidió con una nueva crisis del sistema, ambos elementos generaron al interior de las organizaciones de izquierda una lucha ideológica muy fuerte que estaba relacionada con la estrategia de la lucha a seguir. Fraternidad de Mujeres Salvadoreñas no fue ajena a tal lucha ideológica: Fraternidad de Mujeres Salvadoreñas dejó de existir en 1969. Ese año de 1969 está marcado por la crisis del Estado salvadoreño que recrudece la represión contra la oposición, y es en este contexto que la Fraternidad de Mujeres Salvadoreñas deja de realizar actos públicos y a su vez se vio afectada por la profunda lucha ideológica al interior de la izquierda.

\section{De guerrilleras a feministas: el origen de las organizaciones de mujeres que incorporan la perspectiva de género en El Salvador}

Después de la firma de los Acuerdos de Paz en 1992, analizando la desmovilización de las mujeres combatientes, lisiadas o políticas en 1994, ONUSAL registró un total de 15,009 miembros del FMLN, los que estaban integrados por 8,442 combatientes; 2,474 lisiados no combatientes y 3,983 políticos. El número total de mujeres fue de 4,492 o $29.9 \%$ que representa casi el $30 \%$ del total de personas desmovilizadas. Un poco menos del $30 \%$ de las mujeres afiliadas al FMLN durante la guerra trabajaban en la cocina, mientras que el $15 \%$ estaban asignadas a tareas relacionadas con la salud. Combatientes armadas 
eran alrededor del $15 \%$, y un $11 \%$ ejecutaba funciones de apoyo. El $40 \%$ restante cumplía otro tipo de tareas. Me encontré que fueron ellas quienes tomaron la iniciativa de introducir al interior del FMLN el debate sobre la incorporación de la perspectiva de género integrado con el análisis de clase para interpretar la realidad nacional, posteriormente, al desaparecer el FMLN (como fuerza político-militar) crearon las bases del actual movimiento de mujeres.
Sin embargo, durante el período de guerra y después de su integración a la guerrilla, estas combatientes tuvieron que enfrentar una realidad difícil, en donde prevalecían los prejuicios de género. Aquéllas que llegaron a tener cargo de dirección pagaron un precio muy alto. Las exigencias para mujeres y hombres eran diferentes, para las mujeres que tenían hijos la situación era más compleja:

No sólo había que hacer bien las cosas, sino había que demostrar que se sabían hacer bien... Yo me recuerdo mucho más dura que los otros jefes, o sea más exigente... para que pudieran respetarme los combatientes, para que pudieran aceptarme en la jefatura... Yo creo que las rupturas con la maternidad fueron un elemento muy desgarrador y ser jefa en ese tiempo, 0 asumir jefaturas o tareas de dirección militar era absolutamente contradictorio con asumir la maternidad. Eso no es así con los hombres, porque el vínculo padre e hijo es distinto en esta sociedad. Ojalá fuera así, pero no es así. Ese costo me acuerdo. En una ocasión una de mis hijas se había quebrado un brazo y me avisaron que estaba quebrado el brazo y que me llamaban desde el hospital. Me llega una carta y pido permiso al equipo de la jefatura y me dijeron: "Mirá, vos sabes que ninguno de nosotros puede salir de aquí sin autorización de los compañeros que están en Guazapa. Entonces, como ya dentro de un mes vamos a ir a una reunión, esperémonos mejor." Vaya pues, yo llego a la reunión, estaba en occidente, esperanzada que iba a obtener el permiso para ver a mis hijas. Tenía casi cuatro años de no verlas y, este, lo planteo y me dicen. "Bueno, tenés derecho a un permiso pero tenemos un problema y es que hay que abrir un corredor en occidente." $Y$ entonces el jefe de la zona conocía más Santa Ana que yo. $Y$ entonces me dice: "Lo tiene que ir a ver Antonio, pero si Antonio se va, nadie más que vos se puede quedar en la zona y eso se puede tardar más de 2 ó 3 meses. Si vos salís, la tarea estratégica de abrir corredor se para. Pero no te podemos negar el permiso. Vos lo decidís". Yo me acuerdo de 
lo que lloré esa noche yo decía "Cómo hago, ay, cómo hago, yo quiero ir a ver a mi hija. Tanto tiempo está quebrada del brazo, pero la tarea es urgente. $Y$, además, sabía el costo que iba a tener si yo optaba por aquello. $Y$ me quedé. No pude ver a mi hija sino hasta un año después". (Luciak, 2001, p. 67).

El FMLN no planteó abiertamente los derechos de las mujeres en sus primeros pronunciamientos y programas. Algunas militantes señalaron los siguientes factores que pudieron haber influido para que se diera tal vacío: la fuerte influencia religiosa, el origen predominantemente rural de la base de la organización y la cultura machista que lograba inhibir hasta las más prominentes lideresas. Asimismo, se puede decir que la ausencia de una organización de mujeres con especificidad genérica pudo haber contribuido a tal vacío.

De todas maneras, es insoslayable el protagonismo de las mujeres en la guerra y en el llamado proceso de transición (a partir de 1992). En los años posteriores a la firma de los Acuerdos se vivieron momentos de incertidumbre, de búsqueda, de esperanzas de toda la sociedad salvadoreña por los reinsertados a la vida civil, de un partido que nacía a la vida democrática. Fue notorio que los temas relativos a las mujeres recibieron atención nula o escasa durante las negociaciones de paz, aun cuando había oficiales de la alta jerarquía política participando en el proceso, como Nidia Díaz y otras.

Como sabemos, fue un momento difícil dejar la guerra y entrar a la paz sin dejar completamente su compromiso político; mujeres y hombres enfrentaron, por igual, dificultades para reintegrarse a la sociedad. Sin embargo, las mujeres del FMLN tuvieron que superar obstáculos adicionales debido a su condición genérica. Por ejemplo:

Las combatientes que intentaban regresar con sus familias fueron tratadas como parias por sus propios padres, parientes $e$ hijos, por haber abandonado a éstos durante la guerra y haber elegido la lucha revolucionaria por sobre sus familias.

Mientras ellas eran consideradas "traidoras a sus familias", los hombres eran alabados por "su heroica lucha”. La sociedad salvadoreña, que no difiere de otras, aplicó en ese momento diferentes estándares a los hombres y a las mujeres.

El fenómeno ha sido ya experimentado en otras sociedades que 
han vivido un conflicto armado, así se expresó en El Salvador, se aceptó y se permitió que las mujeres desempeñaran un papel no tradicional, siempre que fue necesario durante el conflicto. Pero una vez terminada la guerra, cuando sus nuevas identidades representaban una amenaza para las relaciones tradicionales de género, se intentó relegarlas a la esfera privada y despojarlas de autoridad. Un estudio realizado en 1993 , sobre 1,100 mujeres del FMLN, deja en evidencia que eso ocurrió. Veamos: antes de la guerra, el $57 \%$ de las mujeres entrevistadas afirmaron que trabajaban fuera del hogar, mientras que un año después de los Acuerdos de Paz, el $95 \%$ se dedicaban al trabajo doméstico. Como una respuesta a la discriminación, con las heridas emocionales aún frescas y con los traumas de la guerra presentes, las mujeres del FMLN orientaron sus energías a contrarrestar la discriminación partidaria y social (Fundación 16 de enero, 1993, p. 5).

De hecho, las primeras expresiones organizativas de mujeres surgidas de las organizaciones político-militares en general tenían como identidad el hecho de ser madres y desde esa condición lucharon por sus hijos e hijas presos, heridos o desaparecidos a causa de la represión.

Estas mujeres organizadas no lo hicieron por iniciativa propia, sino por instrucciones de quienes lideraban las organizaciones beligerantes que comenzaron a ver en ellas cualidades "características o habituales" que las hacían susceptibles de participar en organizaciones legales, sin ser blanco tan fácil de la represión pero que además presentarían el rostro más sensible, el personaje más sufrido de la guerra. (Soriano Hernández, s. f. p. 6).

Obviamente, sus demandas no giraban en torno a sus intereses prácticos o estratégicos, sino a su organización político-militar que representaban y en la cual militaban.

El FMLN concluyó su transformación de un movimiento guerrillero a un partido legal a finales de 1992.
A estas alturas, la influencia de las mujeres feministas ya comenzaba a perfilarse en los documentos. A diferencia de las posiciones que el Frente tuvo durante la guerra, cuando toda referencia a los derechos de las mujeres estaba ausente en los documentos oficiales, en el programa del nuevo partido había una referencia específica a las mujeres:

La edificación de una verdadera democracia supone la plena realización de las mujeres y su participación creadora en todos 
los ámbitos de la vida nacional. Este es un principio fundamental en el proyecto de sociedad por el que lucha el FMLN. Tenemos un compromiso: conseguir la igualdad de derechos para las mujeres, eliminar la superación de su marginación y opresión en la sociedad salvadoreña. (Frente Farabundo Martí para la Liberación Nacional, 1993a, p. 8)

Es precisamente durante este aparece un movimiento poderoso e período de transición cuando innovador:

Basado primero en las militantes revolucionarias-civiles y exguerrilleras a las que poco a poco se suman mujeres de diversos sectores, se afirma desde comienzos de 1992 por medio de numerosas acciones públicas y un proceso de lucha para la democratización, vinculado con una clara toma de autonomía de cara a las orientaciones partidarias. (Falquet, 1998, p. 10).

Las militantes del FMLN que comenzaron a introducir la perspectiva de género lo hicieron, primero, declarando públicamente su apoyo a tal medida, luego señalando la ausencia de la misma medida durante la guerra en los documentos oficiales y no oficiales de la organización. Por supuesto que este señalamiento antes de los Acuerdos de Paz no lo habrían hecho, luego su estrategia fue la creación de la Secretaría de la Mujer con el objetivo de fortalecer su posición dentro del partido.

A manera de epílogo podemos señalar que las mujeres salvadoreñas, ya sea como militantes del partido o como asociadas de las nacientes organizaciones surgidas antes y después de los Acuerdos de Paz, comenzaron una función significativa dentro de la izquierda revolucionaria que ha impactado en la sociedad salvadoreña con los cambios sociopolíticos y jurídicos, esto a partir de la incorporación de la perspectiva de género en sus múltiples quehaceres y facetas. Podemos mencionar algunos factores que contribuyeron a su surgimiento y posterior fortalecimiento:

a. Las múltiples funciones que las mujeres desempeñaron durante la guerra, en la guerrilla y en las organizaciones que desde la sociedad civil apoyaron el proyecto contra hegemónico, 1970-1992.

b. La experiencia organizativa histórica de las mujeres salvadoreñas desde la creación de Fraternidad de Mujeres en 1956. 
c. Las experiencias individuales de mujeres que apoyaron los cambios desde diferentes espacios de acción social.

d. El peso del apoyo internacional y del movimiento feminista internacional y regional a favor de los derechos de las mujeres.

e. La eficacia de las estrategias que perseguían las militantes tanto partidarias como feministas.

\section{Estrategias y avances del Movimiento de Mujeres en El Salvador, 1996-2008}

Desde 1993 a la fecha han transcurrido más de 25 años, y los logros realizados del MMyF son visibles. Además, en el marco de los movimientos sociales, tiene definidas las principales características de los mismos, así la Identidad se refiere a la autodefinición del movimiento $y$ de lo que es a nombre de quien se habla. Se habla a nombre de las mujeres salvadoreñas y de ellas mismas como seres humanos.

Adversario: hace referencia al enemigo principal del movimiento según lo identifica éste de forma explícita. El enemigo principal está definido como el sistema patriarcal ${ }^{3} y$, aunque no es muy explícito, también el sistema capitalista o capitalismo patriarcal.

Visión u objetivo social: se refiere al tipo de orden o de organización social que el movimiento desearía obtener en el horizonte histórico. La utopía es la equidad de género o igualdad de derechos, incluidos los reproductivos.

¿Cuáles han sido las principales estrategias ejecutadas a lo largo de estos años?

\subsection{Incidencia en las instituciones del Estado a nivel nacional y municipal}

Las organizaciones feministas y de mujeres han diseñado e impulsado de manera sostenida estrategias vinculadas con la generación de ingresos, derechos sexuales y derechos reproductivos, erradicación de la violencia contra las mujeres, derechos laborales y empoderamiento de las mujeres. Estas estrategias han sido puestas en marcha a través de procesos de incidencia política frente a instituciones del Estado tanto a nivel nacional como municipal.

Los temas que se han logrado impulsar con otros actores sociales 
son los relacionados con los derechos laborales, erradicación de violencia

contra las mujeres y los derechos reproductivos, fundamentalmente.

\subsection{Lucha por el incremento de la participación política de las mujeres en los espacios de elección popular}

Incrementar la participación política de las mujeres en cargos de elección popular ha sido una apuesta importante y sostenida del movimiento de mujeres desde la visión de contribuir con la transformación del patriarcado y cambiar la representación política en la toma de decisión y del sistema político.

\subsection{La formación-capacitación}

Es central en la generación de conocimientos, en la reflexión y aplicación de los mismos, porque permite que las mujeres a partir de su práctica descubran aquellos elementos que nos identifican como mujeres en nuestra condición histórica, es decir, la construcción social que nos identifica con la sexualidad para otros, lo cual está relacionado con la procreación de la vida. El compromiso asumido por las organizaciones feministas y de mujeres en potenciar iniciativas individuales o colectivas para la generación de ingresos de las mujeres es de reciente data, sin embargo, la articulación de estrategias de financiamiento, formación empresarial, comercialización, asesoría y asistencia técnica dan cuenta de la importancia que esto significa para las mujeres emprendedoras.

Las características que presenta el Movimiento de Mujeres y Feministas después de 1992 lo hacen parecer como un movimiento flexible, creativo y dinámico, lo cual le ha permitido, a manera de ensayo y error, elaborar y ejecutar sus estrategias,

Existen criterios que algunas estudiosas de los movimientos sociales han definido para calificar la pertinencia o no de un movimiento social; el Movimiento de Mujeres y Feministas en El Salvador cumple con esos criterios, los cuales son:

a. Su permanencia en el tiempo, desde 1985-1986, cuando surgieron las primeras organizaciones de mujeres que incorporaron la perspectiva de género hasta la actualidad.

b. La presencia de organizaciones de mujeres en todo el país. En el mapeo nacional de las expresiones organizativas a nivel municipal realizado en 2007 
(Herrera, 2008, p. 14) se informa de 526 organizaciones locales, 11 organizaciones nacionales y 14 redes que articulan a las organizaciones de mujeres y feministas de carácter nacional.

c. Planteamiento de sus demandas a nivel nacional, con análisis feministas, por un cambio cultural $y$ político. Aquí se incluyen aquellos estudios que han tenido como objeto de investigación las situaciones y experiencias de las mujeres en la sociedad, considerándolas como sujetos centrales del proceso y como base para plantear sus demandas.

d. Acciones conjuntas. Ejemplos de acciones conjuntas hay muchas y variadas: nacionales, locales y territoriales en alianzas con el movimiento social o con otros sectores sociopolíticos.

e. Identificación de su adversario. En general, el adversario del Movimiento de Mujeres y Feministas es el sistema patriarcal en el marco de una sociedad capitalista neoliberal, aunque no muy explícito en su carácter de clase, aunque sus acciones han sido enfiladas hacia el Estado. Asimismo fue conformándose su visión definida como una sociedad con equidad de género, y más claramente su identidad como mujeres salvadoreñas.

\subsection{Principales Aportes del MMyF a la sociedad salvadoreña}

a) Incorporación de la perspectiva de género en el análisis de la realidad social.

En esta línea podemos colocar las innumerables investigaciones macro y microsociales que desde la perspectiva de género se han realizado en El Salvador. Los temas más relevantes han sido salud, derechos sexuales y reproductivos, violencia, educación, legislación, organización social y comunitaria, planificación y ejecución de políticas de equidad de género, comunitaria, municipal, nacional, entre otras. b) Identificación de procesos a través de los cuales se mantiene la inequidad entre los géneros.

Al develar de manera científica los orígenes de la subordinación y discriminación de las mujeres e identificar el proceso de socialización que se inicia en la familia, se continúa en la escuela, pasando por la iglesia, el Estado y los medios de comunicación, como los agentes responsables de la estructura de las relaciones de poder, se ha llegado a las raíces de la subordinación y discriminación. 
c) Desarrollo de herramientas para la elaboración e implementación de proyectos y programas hacia la equidad.

Los enfoques que han predominado en la planificación de proyectos dirigidos a las mujeres pobres podemos agruparlos en dos tipologías: Mujer y Familia, Mujer y Comunidad. En estos enfoques no se veía a las mujeres como personas sino como ligadas a la familia y a la comunidad, en la medida que la perspectiva de género fue evolucionado se propusieron dos alternativas de planificación: Mujeres en Desarrollo (MED) y Género en Desarrollo (GED).

\section{d) Aplicación de estrategias que contribuyen a la transformación de las relaciones de género.}

Los gobiernos adoptaron las Estrategias de Nairobi que están orientadas hacia el futuro para el adelanto de la mujer (1985), las cuales esbozaban las medidas para lograr la igualdad de género a nivel nacional y promover la participación de las mujeres en las iniciativas de paz y desarrollo.

Las Estrategias de Nairobi constituyeron un programa actualizado para el futuro de la mujer hasta fines del siglo XX,y sentaron nuevas pautas al declarar que todas las cuestiones estaban relacionadas con la mujer, reconociendo que su participación no era legítima sino indispensable para una comprensión más acabada de la implementación de las políticas públicas para la igualdad de oportunidades, se instó a los gobiernos a que delegaran responsabilidades y crearan programas y espacios institucionales relativos a la mujer en una amplia gama de temas desde el empleo, la salud, la educación y los servicios sociales hasta la industria, la ciencia, las comunicaciones y el medio ambiente.

Además, se propusieron directrices para la adopción de medidas a escala nacional con miras a fomentar la participación de la mujer en la promoción de la paz, así como a prestar asistencia a la mujer en situaciones especiales de peligro.

Las Estrategias de Nairobi se han tomado de base para la formulación de la mayoría de las políticas nacionales para la igualdad y/o equidad que en El Salvador se han aplicado

Todo lo anterior ha sido posible gracias a las luchas internacionales de las mujeres, las acciones de Naciones Unidas desde 1975, con mayor énfasis en los años 90, a los estudios de género y a la pasión de las salvadoreñas por la lucha feminista.

Como muy bien dice Morena Herrera en su reciente artículo: "De la guerrilla al feminismo: nuevos 
caminos en busca de justicia social", aparecido en El Faro el 16 de enero de 2017:

Poco a poco se fue juntando con la fuerza reivindicativa local; con ello, se fueron construyendo espacios institucionales para solventar problemáticas relacionadas con la subordinación femenina en la Asamblea Legislativa, donde funciona el Grupo Parlamentario de Mujeres, Unidades Municipales de la Mujer creadas en alcaldías y Políticas Municipales de Equidad de Género.

La Ley de creación del ISDEMU y la Política Nacional de la Mujer; hoy tenemos los centros Ciudad Mujer, UNIMUJER (Unidades especializadas para atender a mujeres y niñas en situación de violencia de la PNC), Unidades de Género creadas en varios ministerios, la Comisión de la Mujer y la Igualdad de Género formada. Contamos con dos leyes modernas: la Ley especial, integral para una vida libre de violencia para las mujeres y la Ley de igualdad, equidad y erradicación de la discriminación contra las mujeres.

Entre otros avances.

A manera de epílogo:

a. Como hemos señalado en el presente ensayo, las organizaciones de mujeres en El Salvador, aproximadamente desde 1920 a 1992, se caracterizaron por partir de un análisis de la realidad desde la perspectiva de clase social. Es en 1985, cuando comienzan a incorporar la perspectiva de género. Después de los Acuerdos de Paz, de 1992 en adelante, se dio una eclosión de organizaciones de mujeres que conformaron el MMyF. Nuestro trabajo analiza ese sujeto social hasta el 2008. b. Pese a que aún no se ha realizado un balance sobre el impacto y los aportes del MMyF en El Salvador, a la sociedad en general y a los cambios políticos y culturales, en particular, podemos adelantar que colocaron en sus demandas e incidencia política temáticas novedosas e impactantes como el trabajo productivo y reproductivo, mundo público y mundo privado, derechos sexuales y reproductivos, paternidad responsable, entre otros. 
c. Partimos de la evidencia de que el Movimiento de Mujeres y Feministas (MMyF) es un actor social y político, cuyas demandas y propuestas han desafiado al sistema patriarcal en su expresión más evidente: el autoritarismo que prevalece en las esferas políticas, econó- micas, sociales y culturales salvadoreñas.

d. Pese a los avances ya señalados, aún quedan muchos vacíos, siendo uno de ellos la ausencia del análisis de género en las universidades, tanto en la pública como en las privadas.

\section{Referencias bibliográficas}

- Astelarra,J. (2005). Veinte años de Políticas de Igualdad. España: Ediciones Cátedra, Universidad de Valencia, Instituto de la Mujer.

- Bonder, G. (s.f.) Género y Subjetividad: avatares de una relación no evidente. Recuperado de www.modemmujer.org

- Cáceres Prendes, J. (1993). Género, ciudadanía y cultura política en El Salvador, 1930-1959. Seminario Balance Histórico del Estado-Nación Centroamericano, San Salvador, 22-26 de noviembre de 1993.

- De Piero, S. (2005). Organizaciones de la Sociedad Civil Tensiones de una Agenda en Construcción. Argentina: PAIDÓS.

- Falquet, J. (1998). El Movimiento de Mujeres en la "democratización" de pos-guerra en El Salvador. Mimeo.

- Frente Farabundo Martí para la Liberación Nacional (FMLN). (1993a). Documentos Políticos. San Salvador: Ediciones Alternativa. . (1993b). Secretaría de la Mujer. . (1993c). Conclusiones del encuentro nacional de mujeres del FMLN, 21 de agosto. (s.e.)

- Fundación 16 de Enero. (1993). Diagnóstico de la situación actual de la mujer excombatiente. San Salvador.

- Herrera, M. (Coord.). (2008) Movimiento de Mujeres en El Salvador: 20052006. Estrategias y miradas desde el feminismo. San Salvador: Fundación Nacional para el Desarrollo (FUNDE).

- LAS DIGNAS. (2000). Una década construyendo feminismo. San Salvador.

- Luciak, I. A. (2001). Después de la revolución igualdad de género y democracia en El Salvador, Nicaragua y Guatemala. San Salvador: UCA Editores. 
- Martínez López, C. E. y Pax. (1998). Conceptualizaciones y prácticas pacíficas femeninas en las sociedades antiguas. Revista de Historia de Mujeres, Vol. 5 (2), pp. 239-261.

- Mujeres 94. (1996). Plataforma de las mujeres salvadoreñas. San Salvador (s.e).

- Navas, M. C. (1985). Los Movimientos Femeninos en Centro América: 1970-1983. En Menjívar, R. y Camacho, D (Coords.) Movimientos Populares en Centro América. San José, Costa Rica: FLACSO. . (1987). Las Organizaciones de Mujeres en El Salvador: 19751985. (Tesis de Maestría en Estudios Latinoamericanos). UNAM, México. . (1988). Apuntes sobre la situación de la mujer salvadoreña. Congreso sobre Derechos Humanos de las Mujeres, Bogotá, Colombia, 9-10 de abril de 1988. Convocado por el Instituto Latinoamericano de Estudios Sociales (ILSA)

. (2013). Movimiento de Mujeres en El Salvador 1986-2008: Desde su invisibilidad histórica hasta la incorporación de la perspectiva de género. (Tesis de Doctorado en Ciencias Políticas). UNAM, México.

- Soriano Hernández, S. (s.f). La organización de las mujeres a partir de la guerra Nicaragua y El Salvador. CCyDEL-UNAM. México, mimeo.

- Romero, I. (1995). La reinserción de la mujer excombatiente. Un legado de guerra. Revista Realidad N ${ }^{\circ} .22$.

- Vallejo, D. S. de D. (2004). Sociología de Género. Universidad Nacional Autónoma de México, Facultad de Ciencias Políticas y Sociales: Centro de Estudios Sociológicos.

\section{Notas}

1 Se hace uso de la palabra "oleada" parafraseando a autoras como Amelia Valcálcer (2005), quien lo usa en el artículo: La memoria colectiva y los retos del feminismo, en Los desafíos del feminismo ante el siglo XXI. Instituto Andaluz de la Mujer, España, y a D'Atri, Andrea: "Feminismo Latinoamericano. Entre la insolencia de las luchas populares y la mesura de la institucionalización" en Creatividad
Feminista. Según el Diccionario de la Lengua Española, oleada: ola grande; embate y golpe de ola; movimiento impetuoso de mucha gente apiñada.

2 Para una ampliación de esta periodización se puede consultar: Navas Turcios, M. C. (2012). Sufragismo y Feminismo. Visibilizando el protagonismo de las mujeres salvadoreñas. 
Ciudad universitaria: Editorial Universitaria; Navas Turcios, M. C. (2013). Movimiento de Mujeres en El Salvador (1986-2008) Desde su invisibilidad histórica y politica hasta la incorporación de la perspectiva de género. (Tesis de Doctorado en Ciencias Políticas). UNA, México.

3 Sistema patriarcal: sistema de valores, costumbres, prácticas legales, económicas y sociales, que permite la subordinación femenina o término elegido para significar el orden socio-moral y político que mantenía y perpetuaba la jerarquía masculina. Un orden social, económico e ideológico que se reproduce por sus propias prácticas de apoyo con independencia de los derechos adquiridos (Vallejo, 2004, p. 42). 